\title{
Author Correction: An alternative hypothesis for the evolution of same-sex sexual behaviour in animals
}

Julia D. Monk (D), Erin Giglio (D), Ambika Kamath, Max R. Lambert (D) and Caitlin E. McDonough (D)

Correction to: Nature Ecology \& Evolution https://doi.org/10.1038/s41559-019-1019-7, published online 18 November 2019.

In the version of this Perspective originally published, in the first paragraph of the section 'A new model for the evolution of sexual behaviour', the sentence "Evidence in support of these critiques comes from echinoderms, an early branching lineage that most likely bears close resemblance to the ancestral organisms in which sexual behaviours evolved, and which often express both SSB and DSB ${ }^{38-40 \text { " }}$ should have been "Evidence in support of these critiques comes from echinoderms, an early branching lineage relative to vertebrates, which have traits that likely resemble the ancestral organisms in which sexual behaviours evolved (Box 2), and have been found to express both SSB and DSB ${ }^{38-40 "}$. This has now been amended.

Published online: 25 November 2019

https://doi.org/10.1038/s41559-019-1064-2

๑) Springer Nature Limited 2019 